\section{Excess granulation tissue and hair loss following acitretin}

\author{
Francesca Gaudiello, Massimiliano \\ Scalvenzi, Lucia Gallo, Nicola Balato \\ Dipartimento di Patologia Sistematica, \\ Sezione di Dermatologia clinica, \\ allergologica e venereologica, Università \\ di Napoli Federico II, Napoli, Italy
}

\begin{abstract}
Retinoids are routinely used in dermatology for various clinical entities including acne vulgaris, rosacea, hypertrophic scars, strie distensae, psoriasis, disorders of dyskeratinization, cancer prevention and other chronic hyperkeratotic disorders. Oral acitretin therapy is effective in the treatment of psoriasis normalizing cellular differentiation and maturation but clinical side-effects are reported. We describe the occurrence of excess granulation tissue in the nails sulcus and noncicatricial universal alopecia in a psoriatic patient receiving oral acitretin.
\end{abstract}

A 52-year-old white women presented to our observation because she was affected by moderate psoriasis since the age of 43 . Examination revealed red, scaly, disseminated plaques covering a large area of her body. Because of the unresponsiveness to the previous treatments (topical therapies), we started oral acitretin at the dose of $30 \mathrm{mg} /$ day. After 40 days of therapy, psoriasis was well controlled, but an area of granulation tissue was noted in the nails sulcus of both hands (Figure 1). At the same time the patient developed progressive and notable hair loss from the entire body.

The following laboratory studies performed prior to, during and following acitretin therapy, were normal: RBC count, WBC count and differential; sedimentation rate, serum creatinine, LDH, SGOT, SGPT, alkaline phosphatase, total bilirubine, cholesterol and triglycerides, ANA, urinalysis and analysis of thyroid. The histological findings of the granulation tissue included the presence of proliferating microvessels and the dermis contained a dense mixed perivascular cellular infiltrate with numerous plasma cells. Based on these findings, excess granulation tissue and universal alopecia were considered to be acitretininduced. Acitretin was stopped.

After 4 weeks, her hair growth substantially improved and granulation tissues resolved. To facilitate the healing twice a week silvernitrate applications were made on granulation tissue. The patient's hair loss completely reversed in 7 weeks.

Retinoids are routinely used in dermatology for various clinical entities including acne vulgaris, rosacea, hypertrophic scars, strie distensae, psoriasis, disorders of dyskeratinization, cancer prevention and other chronic hyperkeratotic disorders. The most common side effects are mucocutaneous. Most of the side effects of retinoids simulate those of excess vitamin $\mathrm{A}$ administration. Vitamin A promotes mucopolysaccharide synthesis in the granulation tissue of skin wounds in rats which is believed to be essential in the early stages of wound healing. Synthetic retinoid administration may exaggerate the usual state of wound healing, however, as we have seen increased granulation tissue production in patients treated with both isotretinoin and acitretin..$^{1,2}$ In fact shortcontact tretinoin therapy is a novel modality in which to treat chronic ulcers and stimulate the formation of granulation tissue. ${ }^{3}$

The excess granulation tissue reported with retinoids usually appear after 3 to 12 weeks of therapy, but there are reports in which the reaction appeared 6 months after beginning therapy, ${ }^{4}$ and even after the withdraw of the drugs because of the long elimination half-life of etretinate. ${ }^{5}$ In our patient, the lesions developed 40 days after starting the therapy, in accordance with literature.

The granulation tissue response appears to be idiosyncratic and unrelated to either the daily dose of retinoids or the total cumulative
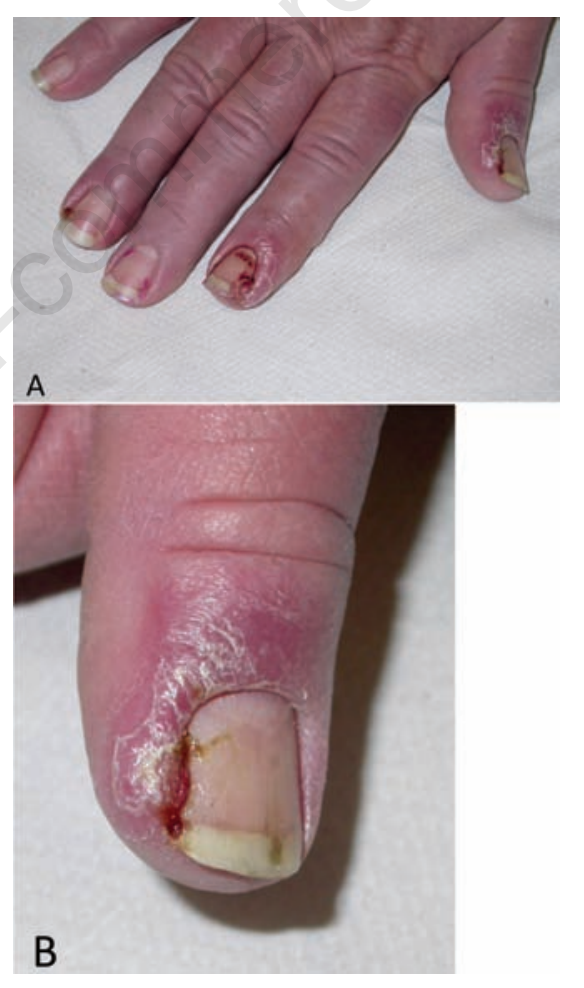

Figure 1. A) Granulation tissue on the first, the second and the fourth nails sulcus of the right hand after $\mathbf{4 0}$ days of therapy with acitretin. B) Detail of the granulation tissue of the first nail sulcus.
Correspondence: Lucia Gallo, Dipartimento di Patologia Sistematica, Sezione di Dermatologia clinica, allergologica e venereologica, Università di Napoli Federico II, via S. Pansini, 580131 Napoli, Italy). E-mail: luc.gallo@libero.it

Key words: psoriasis, acitretin, granulation tissue, alopecia

Conflict of interest: the authors report no conflicts of interest.

Received for publication: 27 June 2010.

Revision received: 29 0ctober 2010.

Accepted for publication: 9 December 2010.

This work is licensed under a Creative Commons Attribution 3.0 License (by-nc 3.0).

(C) Copyright F. Gaudiello et al., 2011

Licensee PAGEPress, Italy

Dermatology Reports 2011; 3:e2

doi:10.4081/dr.2011.e2

dose. ${ }^{2}$ The reaction may resolve spontaneously after the discontinuation of therapy. The formation of excess granulation tissue during retonoids therapy may be explained by several factors: ${ }^{6}$ i) the desquamative reaction at the undersurface of the proximal nail-fold may act a foreign body in the lateral nail groove and incite a clinical inflammatory response; ii) the soft keratin of the nail plate results in fine spicules which emerge from the lateral edges and break through the lateral nail grooves; iii) the fragility of the skin induced by retinoids may allow micro-organism to enter; iv) retinoids significantly inhibits the migration of neutrophilis from blood to tissue. ${ }^{6}$

The prevalence and severity of alopecia depend on the drug as well as on individual predisposition. ${ }^{78}$ Alopecia occurs less frequently with acitretin than with etretinate, ${ }^{9}$ and such rapid and severe alopecia has not been frequently reported in the literature.

\section{References}

1. Robertson DB, Kubiak E, Gomez EC. Excess granulation tissue responses associated with isotretinoin therapy. $\mathrm{Br} \mathrm{J}$ Dermatol 1984;111:689-94.

2. Campbell JP, Grekin RC, Ellis CN, et al. Retinoid therapy is associated with excess granulation tissue responses. J Am Acad Dermatol 1983;9:708-13.

3. Paquette D, Badiavas E, Falanga V. Shortcontact topical tretinoin therapy to stimulate granulation tissue in chronic wounds. J Am Acad Dermatol 2001;45:382-6.

4. Williamson DM, Greenwood R. Multiple pyogenic granulomata occurring during etretinate therapy. Br J Dermatol 1983; 
109:615-7.

5 Bastos PR, Avelleira JC, Cruz MA, et al. Granulation tissue in palpebral conjunctivae associated with acitretin therapy. J Am Acad Dermatol 2008;58:S41-2.

6. Baran R. Etretinate and the nails (study of 130 cases). Possible mechanism of some side-effect. Clin Exp Dermatol 1986;11: 148.

7. Tosti A, Pazzaglia M. Drug reactions affecting hair: diagnosis. Dermatol Clin 2007;25: 223-31.

8. Tosti A, Misciali C, Piraccini BM, et al. Drug-induced hair loss and hair growth.
Incidence, management and avoidance. Drug Saf 1994;10:310-7.

9. Chave TA, Mortimer NJ, Hutchinson PE. Agranulocytosis and total scalp alopecia following acitretin. Br J Dermatol 2003 148:1063-4. 